\title{
EXPLORE
}

\section{Implementasi Metode Backward Chaining untuk Diagnosa Kerusakan Motor Matic Injection}

\author{
Aghy Gilar Pratama, Robby Rizky, Ayu Mira Yunita, Neli Nailul Wardah \\ Fakultas Teknologi dan Informatika \\ Universitas Mathla'ul Anwar Banten \\ Banten, Indonesia \\ Aghy.gp.91@gmail.com, robby_bae87@yahoo.com,ayumira@unmabanten.ac.id, wardahdjupanda@gmail.com
}

\begin{abstract}
The problem that occurs in this research is that there are many workshops that cannot repair new motorbike types of automatic injection technology. If this motorbike is damaged even the slightest, it must still be checked through a computer programmed by the factory. This resulted in the repair shop at the roadside having difficulty repairing the motorbike. Conventional workshops will not have injection motor damage inspection tools like those of authorized workshops. Little by little conventional workshops will be outdated and slowly disappear. Therefore, this study creates an expert system that has the same function as the tools owned by official workshops. The purpose of this research is to help roadside workshops to make repairs as done by official workshops. The method used in this research is the Backward Chaining method. This method performs a backward sequence which is believed to solve the problems that exist in this study. The conclusion in this study is that the backward chaining method can solve problems at Yamaha Albanteni Menes Motor.
\end{abstract}

Keywords: Expert system, Damage diagnosis, Automatic motor, Injection, Backward Chaining

\begin{abstract}
Abstrak-Permasalahan yang terjadi pada penelitian ini yaitu banyak bengkel yang tidak dapat memperbaiki motor produk baru jenis matic yang berteknologi injeksi. Apabila motor ini mengalami kerusakan sekecil apapun tetap harus dilakukan pemeriksaan melalui komputer yang telah diprogram oleh pabrik. Hal ini mengakibatkan bengkel yang berada dipinggir jalan mengalami kesulitan ketika memperbaiki motor tersebut. Bengkel konvensional tidak akan memiliki alat pemeriksaan kerusakan motor injeksi seperti yang dimiliki bengkel resmi. Sedikit demi sedikit bengkel konvensional pun akan tertinggal zaman dan musnah perlahan. Maka dari itu, penelitian ini membuat sebuah system pakar yang memiliki fungsi sama dengan alat yang dimiliki oleh bengkel resmi. Tujuan penelitian ini yaitu membantu agar bengkel dipinggir jalan dapat melakukan perbaikan seperti yang dilakukan bengkel resmi. Metode yang digunakan pada penelitian ini adalah metode Backward Chaining. Metode ini melakukan runut mundur yang dipercaya dapat memecahkan permasalahan yang ada pada penelitian ini. Kesimpulan pada penelitian ini adalah bahwa metode backward chaining dapat memecahkan permasalahan di Yamaha Albanteni Menes Motor.
\end{abstract}

Kata Kunci: Sistem Pakar, Diagnosa Kerusakan, Motor Matic,Injection, Backward Chaining

\section{Pendahuluan}

Motor matic pertama kali di produksi di Indonesia tahun 2007 motor matic berbeda karakter dengan motor pda umumnya motor matic sangat identic dengan perpindahan gigi automatis dan sangat mudah di kendarai.motor matic pada era sekarang sudah menggunakan teknologi injection ,teknologi ini menggunakan ECU sebagai komputer yang mengatur supply bahan bakar dan pengapian pada kendaraan bermotor dengan teknologi ini menjadikan lebih sempurna hasil pembakaranya[1].permasalahan lain yaitu sulitnya bengkel pinggiran untuk memiliki alat pendeteksi kerusakan pada kendaraan injection, alat tersebut hanya di miliki oleh bengkel resmi maka dari itu di buat sebuah Sistem pakar untuk membantu para bengkel pinggiran supaya dapat mendeteksi kerusakan pada kendaraan yang berteknologi injection agar tidak harus selalu ketergantungan ke bengkel resmi[2]. Di era sekarang ini kendaraan bermotor sudah sangat banyak yang memilikinya dan kalangan muda dan orang tua pun pasti memiliki kendaraan bermotor,kendaraan bermotor merupakan sebuah kendaraan yang paling ekonomis dari segi bahan bakar dan perawatan tetapi kendaraan bermotor yang berteknologi injection sangat sulit di lakukan oleh orang awam dan bukan dari bengkel resmi dengan adanya sebuah Sistem pakar ini di harapkan dapat membantu untuk mendeteksi kerusakan sepeda motor injection [3].dalam hal menyelesaikan permaslahan tersebut teknologi komputer dapat di jadikan solusi di karnakan teknologi komputer mengadopsi teknologi Artificial Intelegent yang dapat mengadopsi kecerdasan manusia ke 
dalam sebuah komputer, dengan teknologi Artificial Intelegent dapat membantu pekerjaan manusia dengan cepat dan teliti dalam mencapai tujuan dalam hal pendeteksian kerusakan motor injection[4].berdasarkan dari beberapa kerusakan motor peneliti tertarik menggunakan metode backward chaining di karnakan metode ini menggunakan runut maju untuk mendeteksi kerusakan pada sepeda motor[5].metode Forward chaining merupakan sebuah algoritma runut maju yang dapat mendeteksi kerusakan pada Sistem ecu pada kendaraan bermotor yang berteknologi injection di karnakan algoritma forward chaing di analisis melalui gejala yang alami oleh kerusakan motor tersebut dan setelah itu ketauan hasil yang di alami oleh motor tersebut[6].manfaat bagi pengguna para pengguna tidak akan meraha hawatir jika kendaraan injection tersebut mengalami masalah dan dapat mengatasinya sendiri dengan teliti seperti halnya seorang mekanik handal, dengan di terapkanya Sistem pakar ini[7].sistem pakar yang baik di rancang agar dapat menyelesaikan suatu permasalahan tertentu dengan meniru kerja dari para ahli dengan Sistem pakar ini orang awampun juga dapat di harapkan dapat menyelesaikan masalaha yang cukup rumit dengan menggunakan Sistem pakar ini[7]. Seiring banyaknya pengguna sepeda motor di jalanan ternate menimbulkan masalah baru yaitu pencemaran lingkungan berupa polusi udara dengan metode Backward chaining ini menciptakan sebuah Sistem pakar yang bebas dari pencemaran polusi dan lain lainya[8][9][10].

\section{Metodologi}

\section{A. Metode Pengumpulan Data}

Pengumpulan data yang di lakukan pada penelitian ini menggunakan 3 langkah, langkah pertama yaitu dengan cara wawancara teknik ini dengan mengumpulkan data dengan cara bertanya kepada seorang ahli/pakar di bidangnya secara langsung. Langkah ke dua yaitu dengan cara pengamatan secara langsung terlahap lokasi penelitian dengan mencatat secara langsung terhadap kejadian yang sedang di teliti langkah ketiga dengan cara membaca referensi studi pustaka pengumpulan data dengan cara membaca buku atau dari jurnal yang menjadi referensi yang sedang di lakukan.

\section{B. Metode analisa data}

Metode Analisis data yang peneliti lakukan adalah menganalisa data tentang kerusakan motor yang berkaitan dengan penyakit pada motor dan bagaimana cara penanganan penyakit tersebut agar kedepanya data tersebut dapat di aplikasikan ke dalam sebuah Sistem.

\section{Tahapan Penelitian}

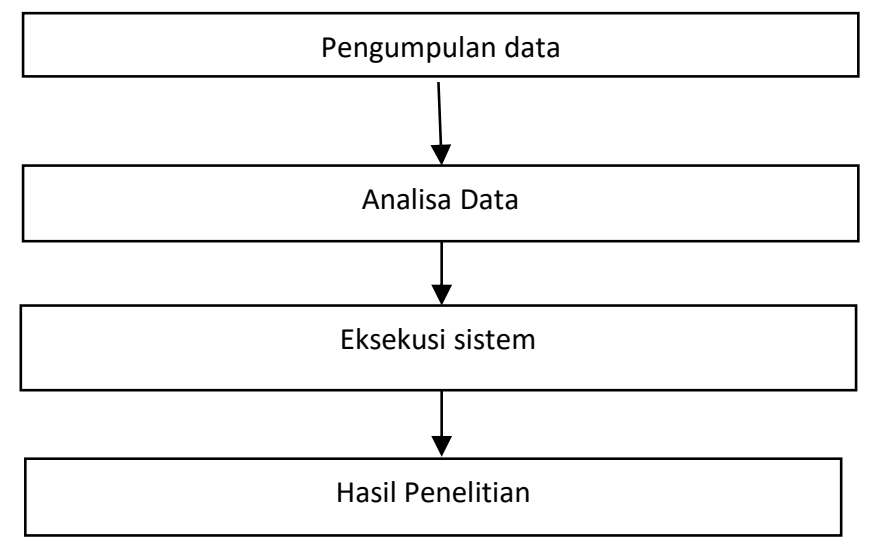

Gambar 1. Tahapan Penelitian(Hasil Penelitian 2018)

Keterangan :

1. Teknik pengumpulan data yaitu proses yang sering di lakukan seperti wawancara dan menyebarkan selembaran kuesioner untuk mengumpulkan tentang Sistem dan kebutuhan dan pilihan.

2. Tehnik analisa data di dalam penelitian ini untuk mengubah data menjadi informasi harus melewati proses analisa yang benar proses ini di gunakan dalam proses sebuah kesimpulan data yang sudah di dapat nanti akan di hitung menggunakan metode Backward chaining.

3. Eksekusi sistem : tahapan ini adalah tahapan memasukan hasil dari pengolahan data tersebut yang nanti akan di tuangkan ke dalam sistem aplikasi .

4. Hasil penelitian merupakan hasil yang nantinya di harapkan dalam penelitian ini.

\section{Hasil dan Pembahasan}


Di dalam jenis kerusakan memeiliki beberapa gejala yang berlainan berikut gejala gejala yang ada pada motor matic injection.

Tabel 1 Data gejala dan kerusakan

\begin{tabular}{|c|c|c|c|c|c|c|c|c|c|c|}
\hline \multirow{2}{*}{$\begin{array}{r}\text { Kode } \\
\text { Gejala }\end{array}$} & \multicolumn{10}{|c|}{ Kode Kerusakan } \\
\hline & K1 & $\mathrm{K} 2$ & K3 & K4 & K5 & K6 & K7 & K8 & K9 & K10 \\
\hline G1 & $\mathrm{X}$ & & $\bar{X}$ & $\mathrm{X}$ & & & & & & \\
\hline G2 & $\mathrm{X}$ & & $\mathrm{X}$ & $\mathrm{X}$ & & & & & & \\
\hline G3 & $\mathrm{X}$ & & $\mathrm{X}$ & $\mathrm{X}$ & & & & & & \\
\hline G4 & & $\mathrm{X}$ & & $\mathrm{X}$ & $\mathrm{X}$ & $\mathrm{X}$ & & & & \\
\hline G5 & $\mathrm{X}$ & & & & & & & & & \\
\hline G6 & & & $\mathrm{X}$ & & & & & & & \\
\hline G7 & & $\mathrm{X}$ & & $\mathrm{X}$ & $\mathrm{X}$ & $\mathrm{X}$ & & & & \\
\hline G8 & & & & & $\mathrm{X}$ & & & & & \\
\hline G9 & & & & & & $\mathrm{X}$ & & & & \\
\hline G10 & & $\mathrm{X}$ & & $\mathrm{X}$ & & & & & & \\
\hline G11 & & & & & & & & $\mathrm{X}$ & & \\
\hline G12 & & & & & & & $\mathrm{X}$ & & & \\
\hline G13 & $\mathrm{X}$ & $\mathrm{X}$ & $\mathrm{X}$ & & & & & $\mathrm{X}$ & & \\
\hline G14 & & & & & $\mathrm{X}$ & $\mathrm{X}$ & & $\mathrm{X}$ & & \\
\hline G15 & & & & & $\mathrm{X}$ & & & & & \\
\hline G16 & & & & & $\mathrm{X}$ & & & & & \\
\hline G17 & & & & & & & & & $\mathrm{X}$ & $\mathrm{X}$ \\
\hline G18 & & & & & & & & & $\mathrm{X}$ & $\mathrm{X}$ \\
\hline G19 & & & & & & & & & $\mathrm{X}$ & \\
\hline G20 & & & & & & & $\mathrm{X}$ & & & \\
\hline G21 & & $\mathrm{X}$ & & & & & & & & \\
\hline G22 & & & & & & & & & $\mathrm{X}$ & $\mathrm{X}$ \\
\hline G23 & & & & & & & & & $\mathrm{X}$ & \\
\hline G24 & & & & & & & & & $\mathrm{X}$ & \\
\hline G25 & & & & & & & & & $\mathrm{X}$ & \\
\hline G26 & & & & & & & & & $\mathrm{X}$ & \\
\hline G27 & & & & & & & & & & $\mathrm{X}$ \\
\hline
\end{tabular}

Tabel 2 Keterangan Kode kerusakan

\begin{tabular}{ccl}
\hline No & Kode Kerusakan & \multicolumn{1}{c}{ Nama Kerusakan } \\
\hline 1 & K1 & Busi \\
2 & K2 & Injektor Kotor \\
3 & K3 & Aki \\
4 & K4 & Fuel Pump \\
5 & K5 & CVT \\
6 & K6 & V-Belt \\
7 & K7 & Roller \\
8 & K8 & Filter Udara \\
9 & K9 & Piston \\
10 & K10 & Ring Piston \\
\hline
\end{tabular}


Tabel 3 Keterangan Kode Gejala

\begin{tabular}{ccl}
\hline No & Kode Gejala & \\
\hline $\mathbf{1}$ & $\mathbf{G 1}$ & Mesin tidak lancar ketika di putar tuas gass / brebet \\
$\mathbf{2}$ & $\mathbf{G}$ & Stater motor sulit tidak terdorong tenaganta/tidak ter angkat \\
$\mathbf{3}$ & $\mathbf{G 3}$ & Ketika di kick stater motor sulit hidup \\
$\mathbf{4}$ & $\mathbf{G} 4$ & Jalan tidak lancar/tersendat sendat \\
$\mathbf{5}$ & $\mathbf{G 5}$ & Knalpot sering mengeluarkan suara tembakan \\
$\mathbf{6}$ & $\mathbf{G 6}$ & Mesin mati total. \\
$\mathbf{7}$ & $\mathbf{G 7}$ & Konsumsi bensin sangat boros \\
$\mathbf{8}$ & $\mathbf{G 8}$ & Dalam keadaan jalan terasa selip disertai muncul \\
& & suara decitan. \\
$\mathbf{9}$ & $\mathbf{G 9}$ & Muncul suara gesekan dari dalam box cvt saat jalan \\
$\mathbf{1 0}$ & $\mathbf{G 1 0}$ & Saat jalan motor tiba tiba mogok/mati \\
$\mathbf{1 1}$ & $\mathbf{G 1 1}$ & Jalan mengalami gangguan/tersendat ketika di atas \\
& & 50km/jam \\
$\mathbf{1 2}$ & $\mathbf{G 1 2}$ & Terdengar suara gemeretak saat jalan didalam box cvt \\
$\mathbf{1 3}$ & $\mathbf{G 1 3}$ & Mesin susah hidup \\
$\mathbf{1 4}$ & $\mathbf{G 1 4}$ & Tarikan motor kurang maksimal \\
$\mathbf{1 5}$ & $\mathbf{G 1 5}$ & Saat handle gas di buka terjadi hentakan kasar dan motor \\
& & loncat loncat \\
$\mathbf{1 6}$ & $\mathbf{G 1 6}$ & Terdengar bunyi kasar saat jalan pelan \\
$\mathbf{1 7}$ & $\mathbf{G 1 7}$ & Mesin mengalami penurunan performa \\
$\mathbf{1 8}$ & $\mathbf{G 1 8}$ & Keluar bau asap menyengat dari knalpot \\
$\mathbf{1 9}$ & $\mathbf{G 1 9}$ & Saat jalan keluar asap pekat mengebul \\
$\mathbf{2 0}$ & $\mathbf{G 2 0}$ & Akselerasi pada putaran atas seperti tertahan \\
$\mathbf{2 1}$ & $\mathbf{G 2 1}$ & Saat idle mesin menyala tidak stabil. \\
$\mathbf{2 2}$ & $\mathbf{G 2 2}$ & Keluar asap putih pekat dari knalpot. \\
$\mathbf{2 3}$ & $\mathbf{G 2 3}$ & Terdengar bunyi mengerik pada mesin \\
$\mathbf{2 4}$ & $\mathbf{G 2 4}$ & Suhu mesin sangat panas \\
\hline & & \\
& & \\
& &
\end{tabular}

Tabel 4 Rule base Backward chaining

\begin{tabular}{|c|c|c|c|}
\hline No & $\begin{array}{c}\text { Kode } \\
\text { Kerusakan }\end{array}$ & Rule & Kaidah Produksi Then \\
\hline \multirow{7}{*}{1} & \multirow{7}{*}{ K1 } & R1 & IF G5 THEN G13 \\
\hline & & $\mathrm{R} 2$ & IF G3 THEN G5 \\
\hline & & R3 & IF G2 THEN G3 \\
\hline & & R4 & IF G1 THEN G2 \\
\hline & & R5 & IF G1 THEN K1 \\
\hline & & R6 & IF G13 THEN G21 \\
\hline & & R7 & IF G10 THEN G13 \\
\hline \multirow[t]{16}{*}{2} & \multirow[t]{16}{*}{ K2 } & $\mathrm{R} 8$ & IF G7 THEN G10 \\
\hline & & R9 & IF G4 THEN G7 \\
\hline & & $\mathrm{R} 10$ & IF G4 THEN K2 \\
\hline & & R11 & IF G6 THEN G13 \\
\hline & & $\mathrm{R} 12$ & IF G3 THEN G6 \\
\hline & & R13 & IF G2 THEN G3 \\
\hline & & R14 & IF G1 THEN G2 \\
\hline & & R15 & IF G1 THEN K3 \\
\hline & & R16 & IF G7 THEN G10 \\
\hline & & R17 & IF G4 THEN G7 \\
\hline & & $\mathrm{R} 18$ & IF G3 THEN G4 \\
\hline & & R19 & IF G2 THEN G3 \\
\hline & & $\mathrm{R} 20$ & IF G1 THEN G2 \\
\hline & & R21 & IF G1 THEN K4 \\
\hline & & $\mathrm{R} 22$ & IF G15 THENG16 \\
\hline & & R23 & IF G14 THEN G15 \\
\hline
\end{tabular}




\begin{tabular}{ll}
\hline R24 & IF G8 THEN G14 \\
R25 & IF G7 THEN G8 \\
R26 & IF G4 THEN G7 \\
R27 & IF G4 THEN K5 \\
R28 & IF G9 THEN G14 \\
R29 & IF G7 THEN G9 \\
R30 & IF G4 THEN G7 \\
R31 & IF G4 THEN K6 \\
R32 & IF G12 THEN G20 \\
R33 & IF G12 THEN K7 \\
R34 & IF G13 THEN G14 \\
R35 & IF G11 THEN G13 \\
R36 & IF G11 THEN K8 \\
R37 & IF G25 THEN G26 \\
R38 & IF G24 THEN G25 \\
R39 & IF G23 THEN G24 \\
R40 & IF G22 THEN G23 \\
R41 & IF G19 THEN G22 \\
R42 & IF 18 THEN K19 \\
R43 & IF G17 THEN G18 \\
R44 & IF G17 THEN K9 \\
R45 & IF G22 THEN 27 \\
R46 & IF G18 THEN G22 \\
R47 & IF G17 THEN G18 \\
R48 & IF G17 THEN K10 \\
&
\end{tabular}

Data Pada Tabel 4 diatas didapat rancangan basis pengetahuan sebagai berikut guna memudahkan dalam proses inferensi.

Tabel 5 Aturan basis pengetahuan sistem pakar

\begin{tabular}{|c|c|c|}
\hline No & Kode Kerusakan & Kaidah Produksi \\
\hline 1 & K1 & $\begin{array}{l}\text { IF KI THEN G1 AND G2 AND G3 AND } \\
\text { G5 AND G13 }\end{array}$ \\
\hline 2 & K2 & $\begin{array}{l}\text { IF K2 THEN G4 AND G7 AND G10 AND G13 } \\
\text { AND G21 }\end{array}$ \\
\hline 3 & K3 & $\begin{array}{l}\text { IF K3 THEN G1 AND G2 AND G3 AND G6 } \\
\text { AND G13 }\end{array}$ \\
\hline 4 & K4 & $\begin{array}{l}\text { IF K4 THEN G1 AND G2 AND G3 AND G4 } \\
\text { AND G7 AND G10 }\end{array}$ \\
\hline 5 & K5 & $\begin{array}{l}\text { IF K5 THEN G4 AND G7 AND G8 AND G14 } \\
\text { AND G15 AND G16 }\end{array}$ \\
\hline 6 & K6 & IF K6 THEN G4 AND G7 AND G9 AND G14 \\
\hline 7 & K7 & IF K7 THEN G12 AND G20 \\
\hline 8 & K8 & $\begin{array}{l}\text { IF K8 THEN G11 AND G13 AND G14 } \\
\text { IF K9 THEN G17 AND G18 AND G19 AND }\end{array}$ \\
\hline 9 & K9 & G22 AND G23 AND G24 AND G25 AND G26 \\
\hline 10 & K10 & $\begin{array}{l}\text { IF K10 THEN G17 AND G18 AND G22 AND } \\
\text { G27 }\end{array}$ \\
\hline
\end{tabular}

Pada Tabel 5 diatas sebuah aturan yang nantinya dapat di bentuk pohon keputusan. 


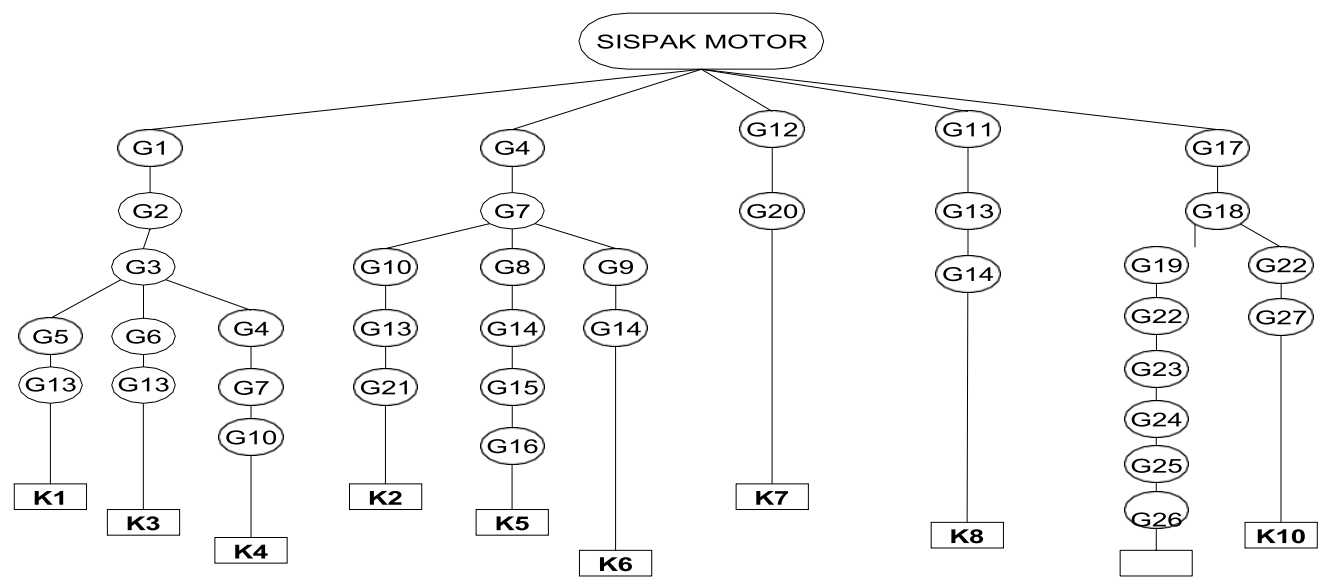

Gambar 2. Tahapan Penelitian(Hasil Penelitian 2018)

\section{Kesimpulan}

Kesimpulan pada penelitian ini adalah bahwa metode Backward chaining di anggap bias memecahkan permaslahan pada penelitian ini di karnakan metode Backward chaining memiliki karakter runut maju yang dapat mendiagnosis sitiap langkah kerusakan pada motor sehingga dapat di analisis kerusakan di setiap unit nya.

\section{Daftar Pustaka}

[1] R. Siregar, "Sistem Pakar Analisa Kerusakan Pada Sepeda Motor Honda Beat Injection Dengan Metode Backward Chaining," Petir, vol. 11, no. 1, pp. 1-8, 2018, doi: 10.33322/petir.v11i1.1.

[2] S. Fachrurrazi, "Implementasi Sistem Pakar Pendeteksian Jenis Kerusakan Sepeda Motor Honda Matic Dengan Menggunakan Metode Forward Chaining," pp. 73-96, 2016, doi: 10.1007/978-1-4613-8911-8_5.

[3] R. D. Efrianto and A. A. Fajrin, "SISTEM PAKAR IDENTIFIKASI KERUSAKAN MOTOR KAWASAKI NINJA 250 CC DENGAN METODE FORWARD CHANNING BERBASIS ANDROID Abstract: refers to the times, expert systems have been used in various fields. In its use an expert system is a system developed to include."

[4] S. Kom and M. Pd, "Sistem Pakar Diagnosa Kerusakan Mesin Sepeda Motor Honda Beat Non Injeksi Menggunakan Metode Backward Chaining Berbasis Berbasis Web," 2015.

[5] A. Sartika Wiguna and I. Harianto, "Sepeda Motor Matic Injeksi Menggunakan Metode Forward," SMARTICS J., vol. 3, no. 1, pp. 25-30, 2017.

[6] D. A. Fauzy, I. Iskandar, J. Rahmadhan, and R. Priambodo, "Aplikasi Bengkel Motor Dengan
Sistem Pakar Menggunakan Metode Forward Chaining," J. Sisfokom (Sistem Inf. dan Komputer), vol. 9, no. 1, p. 89, 2020, doi: 10.32736/sisfokom.v9i1.783.

[7] A. S. Wiguna and I. Harianto, "Sistem Pakar Diagnosa Kerusakan Sepeda Motor Matic Injeksi Menggunakan Metode Forward Chaining Berbasis Android," SMARTICS J., vol. 3, no. 1, pp. 25-30, 2017, doi: 10.21067/smartics.v3i1.1933.

[8] M. S. F., "Sistem Pakar Untuk Mendeteksi Kerusakan Pada Sepeda Motor 4-tak Dengan Menggunakan Metode Backward Chaining," Explor. J. Sist. Inf. dan Telemat., vol. 4, no. 2, 2014, doi: 10.36448/jsit.v4i2.540.

[9] R. Rizky, M. Ridwan, and Z. Hakim, "Implementasi Metode Forward Chaining Untuk Diagnosa Penyakit Covid 19 Di Rsud Berkah Pandeglang Banten," J. Teknol. Inf., vol. 4, no. 1, pp. 1-4, 2020.

[10] Z. Hakim and R. Rizky, "Sistem Pakar Menentukan Karakteristik Anak Kebutuhan Khusus Siswa Di SLB Pandeglang Banten Dengan Metode Forward Chaining," JUTIS (Jurnal Tek. Inform. ) Progr. Stud. Tek. Inform. Tek. Univ., vol. 7, no. 1, pp. 93-99, 2019.

[11] E. Borgia, "The internet of things vision: Key features, applications and open issues," Comput. Commun., vol. 54, pp. 1-31, 2014, doi: 10.1016/j.comcom.2014.09.008.

[12] K. Seemanthini and S. S. Manjunath, "Human Detection and Tracking using HOG for Action Recognition," Procedia Comput. Sci., vol. 132, no. Iccids, pp. 1317-1326, 2018, doi: 10.1016/j.procs.2018.05.048.

[13] K. Hägglund, "The SMART HOME REVOLUTION.," Appl. Des., vol. 63, no. 1, pp. 16-19, 2015. 